\title{
HIGH-PRECISION BIDECADAL CALIBRATION OF THE RADIOCARBON TIME SCALE, 500-2500 BC
}

\section{GORDON W. PEARSON}

Retired from Palaeoecology Centre, The Queen's University of Belfast, Belfast, BT71NN, Northern Ireland

and

\section{MINZE STUIVER}

Department of Geological Sciences and Quaternary Research Center, University of Washington, Seattle, Washington 98195 USA

\section{INTRODUCTION}

The sole purpose of this paper is to present a previously published ${ }^{14} \mathrm{C}$ data set to which minor corrections have been applied. All basic information previously given is still applicable (Pearson $\&$ Stuiver 1986). The corrections are needed because ${ }^{14} \mathrm{C}$ count-rate influences (radon decay in Seattle, a re-evaluation of the corrections applied for efficiency variation with time previously unrecognized in Belfast) had to be accounted for in more detail. Information on the radon correction is given in Stuiver and Becker (1993). The Belfast corrections were necessary because the original correction for efficiency variations with time was calculated using two suspect standards (these were shown to be suspect by recent observations) that overweighted the correction. A re-evaluation (Pearson \& Qua 1993) now shows it to be almost insignificant, and the corrected dates (using the new correction) became older by about 16 years.

Systematic ${ }^{14} \mathrm{C}$ age differences between the current Seattle and Belfast data sets are 9.9, 16.6 and $2.4{ }^{14} \mathrm{C}$ yr for, respectively, the $1-1000 \mathrm{BC}, 1001-2000 \mathrm{BC}$ and $2001-3000 \mathrm{BC}$ intervals. Reproducibility can be expressed by an error multiplier, $\mathrm{K}_{\text {Seattle-Belfass }}$ which is defined as the ratio of the actual standard deviation in the age differences and the average standard deviation of the differences calculated from the quoted errors in the ${ }^{14} \mathrm{C}$ determinations. $\mathrm{K}$ values for the above intervals are, respectively, 1.3, 1.4 and 1.8. A detailed discussion of the offsets and $\mathrm{K}$ values for the AD 1840-6000 BC interval is given in Stuiver and Pearson $(1992,1993)$. Here we note: 1) the Table 1 Seattle-Belfast bidecadal conventional (Stuiver \& Polach 1977) ${ }^{14} \mathrm{C}$ age averages may be subject to systematic errors of $5-8{ }^{14} \mathrm{C}$ yr maximally; and 2) the standard deviations given with the bidecadal ${ }^{14} \mathrm{C}$ ages are based on quoted errors multiplied with $\mathrm{K}_{\text {Belfast }}=1.23$ and $\mathrm{K}_{\text {Seattle }}=1.6$, and thus account for $90-100 \%$ of the variance encountered in the Seattle-Belfast ${ }^{14} \mathrm{C}$ age differences. Details on K determinations can be found, e.g., in Stuiver and Pearson (1986).

Seattle-Belfast bidecadal ${ }^{14} \mathrm{C}$ age averages for the $\mathrm{AD} 1840-500 \mathrm{BC}$ and $2500-6000 \mathrm{BC}$ interval are given in a twin paper (Stuiver \& Pearson 1993).

\section{CALibration instructions}

We recommend that users of ${ }^{14} \mathrm{C}$ dates obtain additional information on reproducibility (and systematic error, if any) from the laboratory reporting the ${ }^{14} \mathrm{C}$ date. This information should lead to a realistic standard deviation in the reported age. A systematic error has to be deducted from, or added to, the reported ${ }^{14} \mathrm{C}$ age prior to age calibration. 
Only the calibration curve is given in Figure 1; the one-sigma ( $1 \sigma$; standard deviation) uncertainty in the curve is not given. The actual standard deviation (averaging $12.9{ }^{14} \mathrm{C} \mathrm{yr}$ for the nearly 8000 cal yr bidecadal calibration curve of Belfast-Seattle ${ }^{14} \mathrm{C}$ age averages) is tabulated in Table 1 for each bidecadal midpoint.

Cal BP ages are relative to the year $\mathrm{AD} 1950$, with 0 cal BP equal to $\mathrm{AD} 1950$. The relationship between cal $\mathrm{AD} / \mathrm{BC}$ and cal $\mathrm{BP}$ ages is cal BP $=1950-\mathrm{cal} \mathrm{AD}$, and cal BP $=1949+\mathrm{cal} \mathrm{BC}$. The switch from 1950 to 1949 when converting $\mathrm{BC}$ ages is caused by the absence of the zero year in the $\mathrm{AD} / \mathrm{BC}$ chronology.

The conversion of a ${ }^{14} \mathrm{C}$ age to a cal age is as follows: 1) draw line A parallel to the bottom axis through the ${ }^{14} \mathrm{C}$ age to be converted; 2) draw vertical line(s) through the intercept(s) of line $\mathrm{A}$ and the calibration curve. The cal $\mathrm{AD} / \mathrm{BC}$ ages can be read at the bottom axis, the cal $\mathrm{BP}$ ages at the top.

To convert the standard error in the ${ }^{14} \mathrm{C}$ age into a range of cal $\mathrm{AD} / \mathrm{BC}(\mathrm{BP})$ ages, determine the sample standard deviation, $\sigma$, by multiplying the quoted laboratory standard deviation by the "error multiplier". Unfortunately, information on error multipliers is often lacking. Here, the ${ }^{14} \mathrm{C}$ age user should refer to K values given in Stuiver and Pearson $(1992,1993)$ or Scott, Long \& Kra (1990).

Once the sample $\sigma$ is known, the curve $\sigma$ should be read from Table 1 . The curve $\sigma$ and sample $\sigma$ should then be used to calculate total $\sigma=\left((\text { sample } \sigma)^{2}+(\text { curve } \sigma)^{2}\right)^{1 / 2}$ (Stuiver 1982). Lines parallel to A should now be drawn through the ${ }^{14} \mathrm{C}$ age + total $\sigma$, and ${ }^{14} \mathrm{C}$ age - total $\sigma$ value. The vertical lines drawn through the intercepts now yield the outer limits of possible cal $\mathrm{AD} / \mathrm{BC}$ (cal BP) ages that are compatible with the sample standard deviation.

The conversion procedure yields 1) single or multiple cal $\mathrm{AD} / \mathrm{BC}(\mathrm{BP})$ ages that are compatible with a certain ${ }^{14} \mathrm{C}$ age, and 2) the range(s) of cal ages that correspond(s) to the standard deviation in the ${ }^{14} \mathrm{C}$ age (and calibration curve). Here, the user determines the calibrated ages from the Figure 1 graphs by drawing lines, whereas an alternate approach would be to use the computerized calibration (CALIB) program discussed elsewhere in this issue (Stuiver \& Reimer 1993).

The probability that a certain cal age is the actual sample age may be quite variable within the cal age range. Higher probabilities are encountered around the intercept ages. The non-linear transform of a Gaussian standard deviation around a ${ }^{14} \mathrm{C}$ age into cal $\mathrm{AD} / \mathrm{BC}$ (cal $\mathrm{BP}$ ) age is not a simple matter, and computer programs are needed to derive the complex probability distribution. The CALIB program incorporates such probability distributions.

The calibration data presented here are valid for northern hemispheric samples that were formed in equilibrium with atmospheric ${ }^{14} \mathrm{CO}_{2}$. Systematic age differences are possible for the southern hemisphere where ${ }^{14} \mathrm{C}$ ages of wood samples tend to be about $40 \mathrm{yr}$ older (Vogel et al. 1993). Thus, ${ }^{14} \mathrm{C}$ ages of southern hemispheric samples preceding our era of fossil-fuel combustion should be reduced by $40 \mathrm{yr}$ before being converted into cal $\mathrm{AD} / \mathrm{BC}(\mathrm{BP})$ ages.

The Figure 1 calibration points are the midpoints of wood samples spanning $20 \mathrm{yr}$. Samples submitted for dating may cover shorter or longer intervals. The decadal calibration results of the Seattle laboratory (Stuiver \& Becker 1993; Stuiver \& Reimer 1993) provide a better time resolution, whereas the CALIB program also has an option to use Figure 1 moving averages (e.g., a 5-point or 100-yr moving average of the bidecadal curve). The latter should be used for a sample grown over a 100-yr interval. Samples formed over intervals longer than a decade or bidecade are very desirable as the ${ }^{14} \mathrm{C}$ "wiggles" of the calibration curve have less influence on the (midpoint) cal age when a smoothed (moving average) calibration curve is used (Stuiver 1992). 
The calibration curve is valid only for age conversion of samples that were formed in equilibrium with atmospheric $\mathrm{CO}_{2}$. Conventional ${ }^{14} \mathrm{C}$ ages of materials not in equilibrium with atmospheric reservoirs do not take into account the offset in ${ }^{14} \mathrm{C}$ age that may occur (Stuiver \& Polach 1977). This constant offset, or reservoir deficiency, must be deducted from the reported ${ }^{14} \mathrm{C}$ age before any attempt can be made to convert to cal $\mathrm{AD} / \mathrm{BC}(\mathrm{BP})$ ages.

The reservoir deficiency is time dependent for the mixed (and deep) layer of the ocean. For the calibration of marine samples in this time domain, the reader is referred to Stuiver and Braziunas (1993) and, of course, the CALIB program.

\section{ACKNOWLEDGMENTS}

The ${ }^{14} \mathrm{C}$ research at Seattle was supported by a National Science Foundation grant BNS-9004492, and by a SERC grant in Belfast. We thank Dr. B. Becker of the University of Hohenheim, Stuttgart for providing German oak (unified Donau/Main series) samples, Drs. J. R. Pilcher and M. G. Baillie for the wood samples of the Irish chronology, and F. Qua, P. J. Reimer and P. J. Wilkinson for crucial technical and analytical support.

\section{REFERENCES}

Pearson, G. W. and Qua, F. 1993 High-precision ${ }^{14} \mathrm{C}$ measurement of Irish oaks to show the natural ${ }^{14} \mathrm{C}$ variations from AD 1840-5000 BC: A correction. Radiocarbon, this issue.

Pearson, G. W., and Stuiver, M. 1986 High-precision calibration of the radiocarbon time scale, 500-2500 BC. In Stuiver, M. and Kra, R. S., eds., Proceedings of the 12th International Radiocarbon Conference. Radiocarbon 28(2B): 839-862.

Scott, E. M., Long, A. and Kra, R., eds. 1990 Proceedings of the International Workshop on Intercomparison of Radiocarbon Laboratories: Radiocarbon 32(3): 253-397.

Stuiver, M. 1982 A high-precision calibration of the $A D$ radiocarbon time scale. Radiocarbon 24(1): 1-26.

1992 How accurate are our chronologies of the past? I: Time warps caused by the transformation of ${ }^{14} \mathrm{C}$ ages. Proceedings of the Dahlem Workshop on Global Changes in the Perspective of the Past. Chichester, John Wiley \& Sons, in press.

Stuiver, M. and Becker, B. 1993 High-precision decadal calibration of the radiocarbon time scale AD 19506000 BC. Radiocarbon, this issue.

Stuiver, M. and Braziunas, T. F. 1993 Modeling radio-

carbon ages of marine samples back to $10,000 \mathrm{BC}$. Radiocarbon, this issue.

Stuiver, M. and Pearson, G. W. 1986 High-precision calibration of the radiocarbon time scale, AD 1950500 BC. In Stuiver, M. and Kra, R. S., eds., Proceedings of the 12th International Radiocarbon Conference. Radiocarbon 28(2B): 805-838.

1992 Calibration of the radiocarbon time scale 2500-5000 BC. In Taylor, R. E., Long, A. and Kra, R. S., eds., Radiocarbon After Four Decades: An Interdisciplinary Perspective. New York, Springer Verlag: 19-33.

1993 High-precision bidecadal calibration of the radiocarbon time scale, AD 1950-500 BC and 25006000 BC. Radiocarbon, this issue.

Stuiver, M. and Polach, H. 1977 Discussion: Reporting of ${ }^{14} \mathrm{C}$ data. Radiocarbon 19(3): 355-363.

Stuiver, M. and Reimer, P. J. 1993 Extended ${ }^{14} \mathrm{C}$ database and revised CALIB radiocarbon age calibration program. Radiocarbon, this issue.

Vogel, J. C., Fuls, A., Visser, E. and Becker, B. 1993 Pretoria calibration curve for short-lived samples, 1930 BC-3350 BC. Radiocarbon, this issue. 


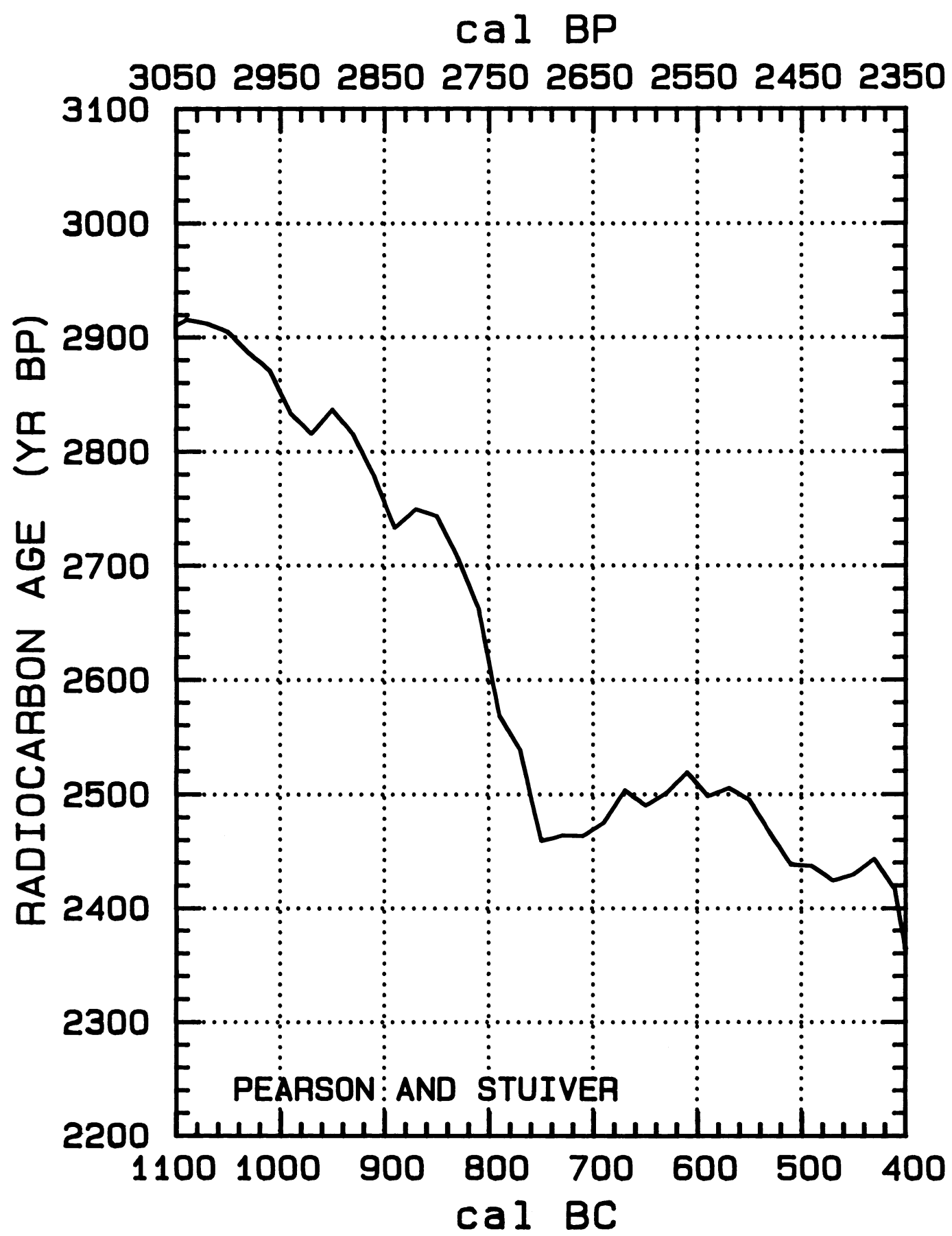

Fig. 1A-D. ${ }^{14} \mathrm{C}$ calibration curve derived from bidecadal samples 


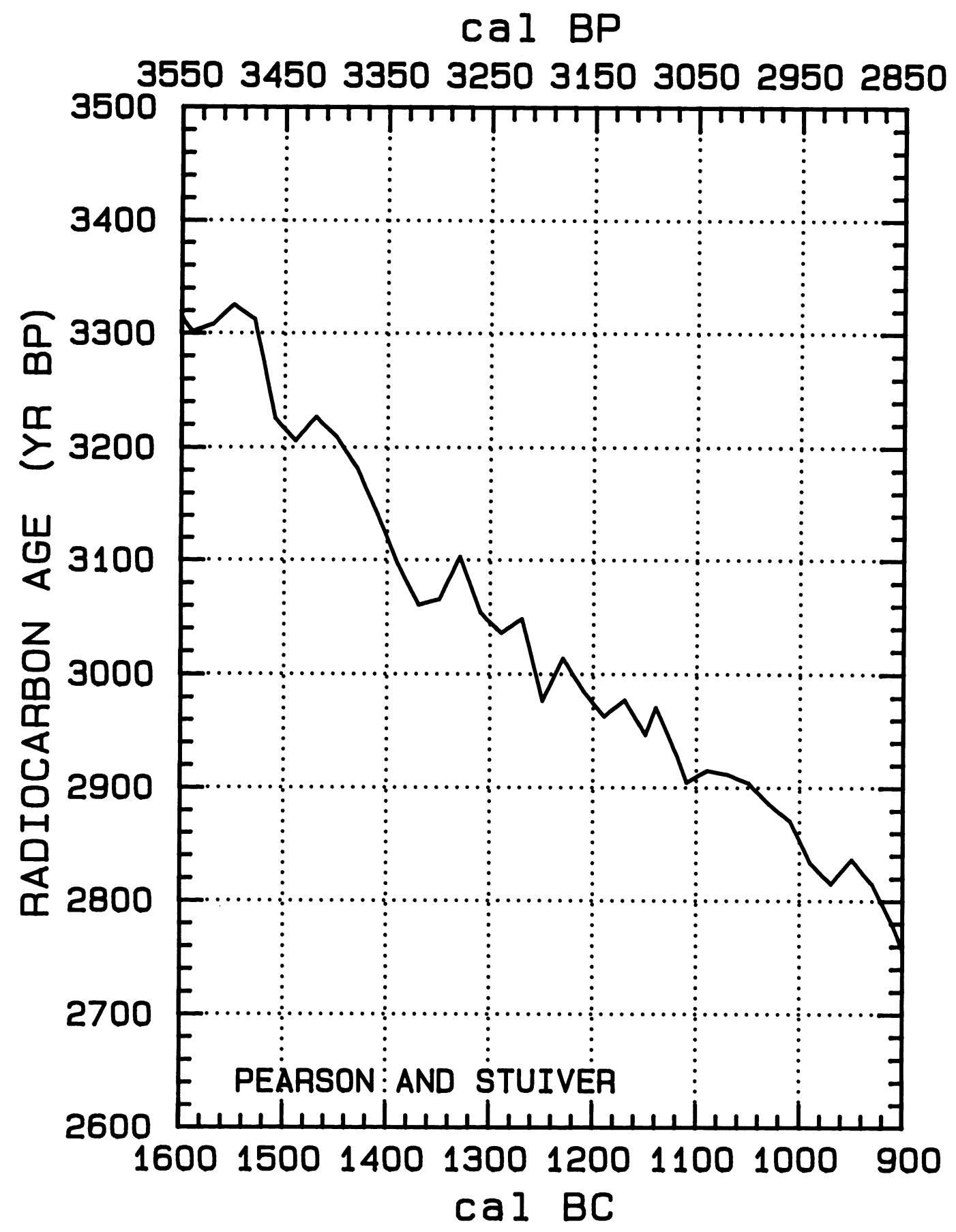

Fig. 1B 


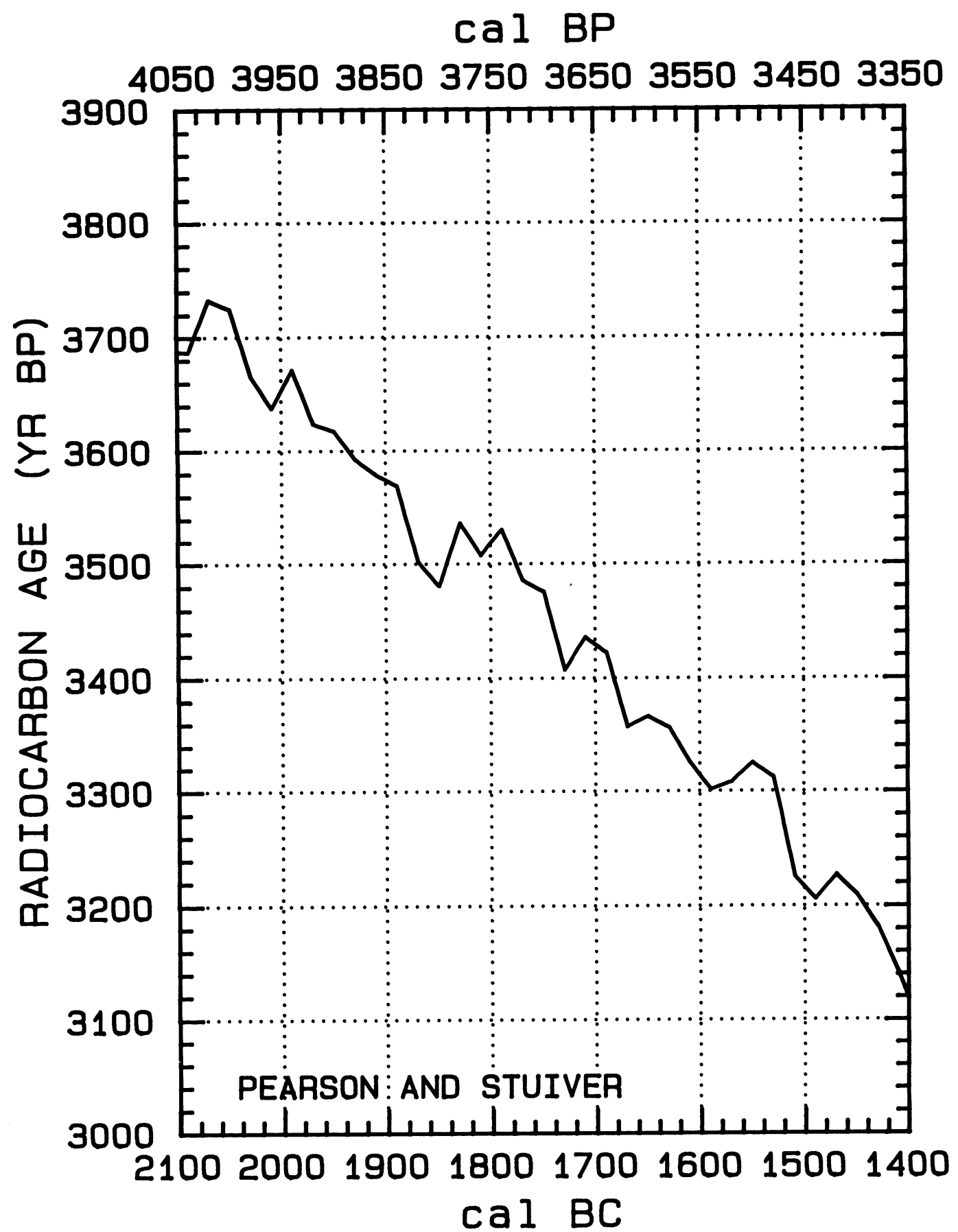

Fig. 1C 


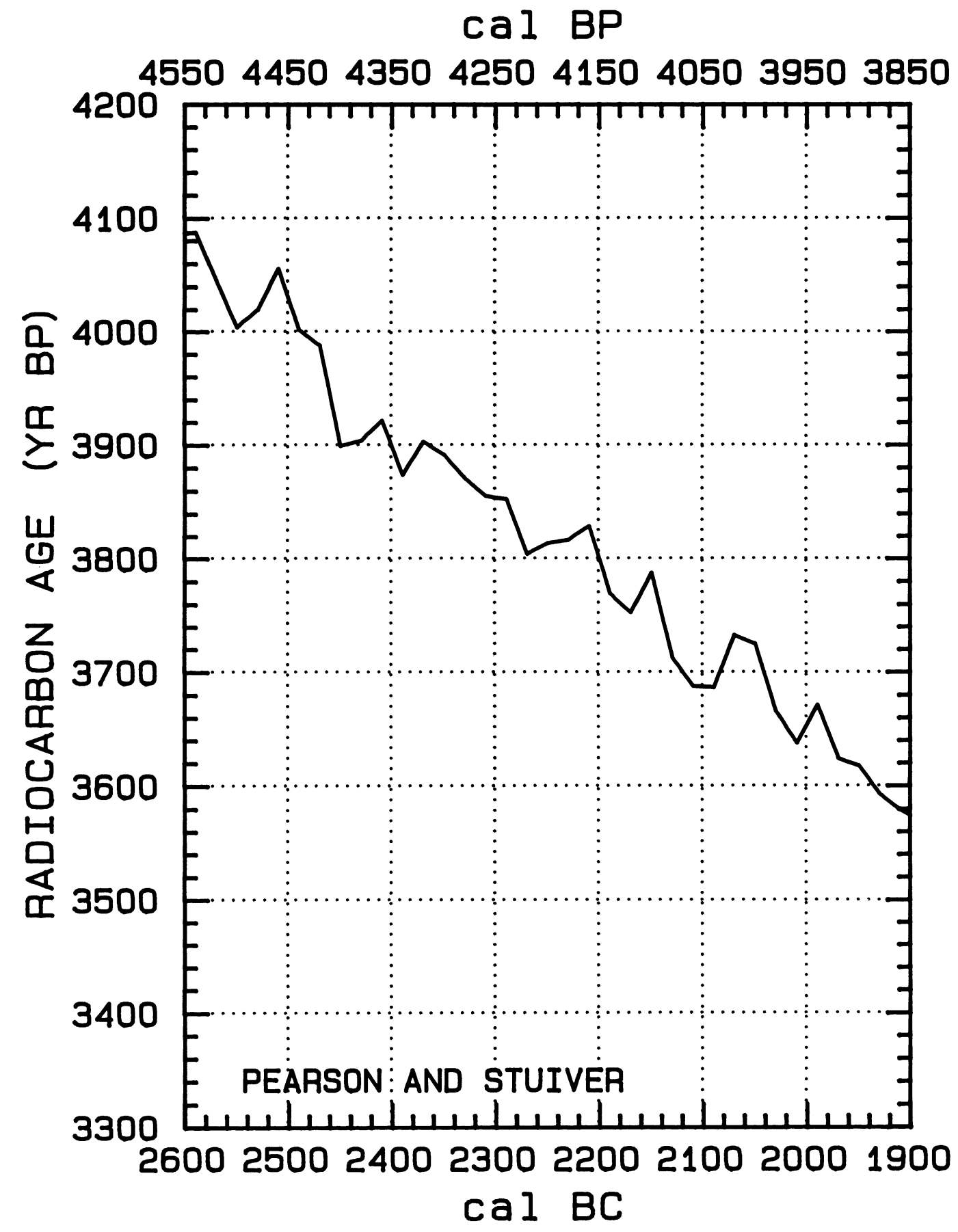

Fig. 1D 
TABLE 1. Weighted averages of University of Belfast and the University of Washington (Seattle) ${ }^{14} \mathrm{C}$ age determinations. The cal $\mathrm{AD} / \mathrm{BC}$ (or cal BP) ages represent the midpoints of bidecadal wood sections, except as noted in the text. The standard deviation in the ages and $\Delta^{14} \mathrm{C}$ (defined in Stuiver and Polach 1977) values includes lab error multipliers of 1.23 for Belfast and 1.6 for Seattle.

\begin{tabular}{|c|c|c|c|c|c|c|c|}
\hline \multicolumn{4}{|c|}{${ }^{14} \mathrm{C}$} & \multicolumn{4}{|c|}{${ }^{14} \mathrm{C}$} \\
\hline Cal $\mathrm{AD} / \mathrm{BC}$ & $\Delta^{14} \mathrm{C} \% 0$ & age (BP) & Cal BP & Cal AD/BC & $\Delta^{14} \mathrm{C} \% 0$ & age (BP) & Cal BP \\
\hline $510 \mathrm{BC}$ & $-6.0 \pm 1.2$ & $2438 \pm 10$ & BP 2459 & $1350 \mathrm{BC}$ & $17.6 \pm 1.8$ & $3066 \pm 14$ & BP 3299 \\
\hline $530 \mathrm{BC}$ & $-7.1 \pm 1.1$ & $2466 \pm 9$ & BP 2479 & $1370 \mathrm{BC}$ & $20.7 \pm 1.8$ & $3061 \pm 14$ & BP 3319 \\
\hline $550 \mathrm{BC}$ & $-8.2 \pm 1.0$ & $2495 \pm 8$ & BP 2499 & $1390 \mathrm{BC}$ & $18.7 \pm 1.5$ & $3096 \pm 12$ & BP 3339 \\
\hline $570 \mathrm{BC}$ & $-7.1 \pm 1.3$ & $2505 \pm 11$ & BP 2519 & $1410 \mathrm{BC}$ & $15.4 \pm 1.6$ & $3141 \pm 13$ & BP 3359 \\
\hline $590 \mathrm{BC}$ & $-3.9 \pm 1.3$ & $2498 \pm 11$ & BP 2539 & $1430 \mathrm{BC}$ & $12.7 \pm 1.5$ & $3182 \pm 12$ & BP 3379 \\
\hline $610 \mathrm{BC}$ & $-4.0 \pm 1.2$ & $2519 \pm 10$ & BP 2559 & $1450 \mathrm{BC}$ & $11.7 \pm 1.1$ & $3210 \pm 9$ & BP 3399 \\
\hline $630 \mathrm{BC}$ & $0.6 \pm 1.2$ & $2501 \pm 9$ & BP 2579 & $1470 \mathrm{BC}$ & $11.9 \pm 1.4$ & $3227 \pm 11$ & BP 3419 \\
\hline $650 \mathrm{BC}$ & $4.4 \pm 1.3$ & $2490 \pm 10$ & BP 2599 & $1490 \mathrm{BC}$ & $17.1 \pm 1.6$ & $3206 \pm 13$ & BP 3439 \\
\hline $670 \mathrm{BC}$ & $5.2 \pm 1.6$ & $2503 \pm 13$ & BP 2619 & $1510 \mathrm{BC}$ & $17.0 \pm 1.7$ & $3226 \pm 14$ & BP 3459 \\
\hline $690 \mathrm{BC}$ & $11.2 \pm 1.8$ & $2475 \pm 14$ & BP 2639 & $1530 \mathrm{BC}$ & $8.5 \pm 1.6$ & $3313 \pm 13$ & BP 3479 \\
\hline $710 \mathrm{BC}$ & $15.1 \pm 2.0$ & $2464 \pm 16$ & BP 2659 & $1550 \mathrm{BC}$ & $9.3 \pm 1.8$ & $3326 \pm 15$ & BP 3499 \\
\hline $730 \mathrm{BC}$ & $17.5 \pm 1.5$ & $2464 \pm 12$ & BP 2679 & $1570 \mathrm{BC}$ & $14.0 \pm 2.1$ & $3308 \pm 17$ & BP 3519 \\
\hline $750 \mathrm{BC}$ & $20.6 \pm 1.7$ & $2459 \pm 14$ & BP 2699 & $1590 \mathrm{BC}$ & $17.3 \pm 1.5$ & $3301 \pm 12$ & BP 3539 \\
\hline $770 \mathrm{BC}$ & $13.1 \pm 2.0$ & $2538 \pm 16$ & BP 2719 & $1610 \mathrm{BC}$ & $16.7 \pm 1.5$ & $3326 \pm 12$ & BP 3559 \\
\hline $790 \mathrm{BC}$ & $11.7 \pm 1.3$ & $2568 \pm 10$ & BP 2739 & $1630 \mathrm{BC}$ & $15.1 \pm 1.6$ & $3357 \pm 12$ & BP 3579 \\
\hline $810 \mathrm{BC}$ & $2.3 \pm 1.6$ & $2662 \pm 13$ & BP 2759 & $1650 \mathrm{BC}$ & $16.3 \pm 1.3$ & $3367 \pm 10$ & BP 3599 \\
\hline $830 \mathrm{BC}$ & $-0.8 \pm 1.5$ & $2707 \pm 12$ & BP 2779 & $1670 \mathrm{BC}$ & $20.0 \pm 1.7$ & $3357 \pm 14$ & BP 3619 \\
\hline $850 \mathrm{BC}$ & $-2.9 \pm 1.6$ & $2743 \pm 13$ & BP 2799 & $1690 \mathrm{BC}$ & $14.2 \pm 1.6$ & $3423 \pm 12$ & BP 3639 \\
\hline $870 \mathrm{BC}$ & $-1.3 \pm 1.6$ & $2750 \pm 13$ & BP 2819 & $1710 \mathrm{BC}$ & $15.0 \pm 1.9$ & $3436 \pm 15$ & BP 3659 \\
\hline 890 BC & & $2733 \pm 13$ & PP 2839 & $1730 \mathrm{BC}$ & $21.1 \pm 1.6$ & $3407 \pm 12$ & BP 3679 \\
\hline $910 \mathrm{BC}$ & $-0.1 \pm 1.5$ & $2779 \pm 12$ & BP 2859 & $1750 \mathrm{BC}$ & $14.9 \pm 1.6$ & $3476 \pm 12$ & BP 3699 \\
\hline $930 \mathrm{BC}$ & $-2.1 \pm 1.7$ & $2815 \pm 13$ & BP 2879 & $1770 \mathrm{BC}$ & $16.1 \pm 1.4$ & $3486 \pm 11$ & BP 3719 \\
\hline $950 \mathrm{BC}$ & $-2.4 \pm 1.5$ & $2837 \pm 12$ & BP 2899 & $1790 \mathrm{BC}$ & $12.8 \pm 1.4$ & $3531 \pm 11$ & BP 3739 \\
\hline $970 \mathrm{BC}$ & $7 \pm 1.3$ & $2815 \pm 10$ & BP 2919 & $1810 \mathrm{BC}$ & $18.2 \pm 1.5$ & $3508 \pm 12$ & BP 3759 \\
\hline $990 \mathrm{BC}$ & \pm 1.4 & $2833 \pm 11$ & BP 2939 & $1830 \mathrm{BC}$ & $17.0 \pm 1.9$ & $3537 \pm 15$ & BP 3779 \\
\hline $\mathrm{BC}$ & & $2871 \pm 9$ & BP 2959 & $\mathrm{BC}$ & \pm 1.7 & $3481 \pm 13$ & BP 3799 \\
\hline 1030 BC & $1.1 \pm 1.5$ & $2886 \pm 12$ & BP 2979 & $1870 \mathrm{BC}$ & $26.4 \pm 1.5$ & $3502 \pm 12$ & BP 3819 \\
\hline $1050 \mathrm{BC}$ & $1.2 \pm 1.3$ & $2905 \pm 10$ & BP 2999 & $1890 \mathrm{BC}$ & $20.3 \pm 1.6$ & $3569 \pm 12$ & BP 3839 \\
\hline $1070 \mathrm{BC}$ & $2.7 \pm 1.3$ & $2912 \pm 11$ & BP 3019 & $1910 \mathrm{BC}$ & $21.5 \pm 1.9$ & $3579 \pm 15$ & BP 3859 \\
\hline $1090 \mathrm{BC}$ & $4.7 \pm 1.3$ & $2916 \pm 11$ & BP 3039 & $1930 \mathrm{BC}$ & $22.2 \pm 1.5$ & $3593 \pm 12$ & BP 3879 \\
\hline $1110 \mathrm{BC}$ & $8.4 \pm 1.4$ & $2905 \pm 11$ & BP 3059 & $1950 \mathrm{BC}$ & $21.5 \pm 1.6$ & $3618 \pm 13$ & BP 3899 \\
\hline $1120 \mathrm{BC}$ & $6.6 \pm 1.7$ & $2930 \pm 14$ & BP 3069 & $1970 \mathrm{BC}$ & $23.1 \pm 1.8$ & $3624 \pm 14$ & BP 3919 \\
\hline 114 & & $2972 \pm 12$ & 3089 & & 1.4 & $3672 \pm 11$ & BP 3939 \\
\hline $1150 \mathrm{BC}$ & $8.1 \pm 1.7$ & $2947 \pm 14$ & BP 3099 & $2010 \mathrm{BC}$ & $26.4 \pm 1.7$ & $3638 \pm 13$ & BP 3959 \\
\hline $1170 \mathrm{BC}$ & $6.6 \pm 1.7$ & $2978 \pm 13$ & BP 3119 & $2030 \mathrm{BC}$ & $25.3 \pm 1.5$ & $3666 \pm 12$ & BP 3979 \\
\hline $1190 \mathrm{BC}$ & $10.9 \pm 1.7$ & $2963 \pm 14$ & BP 3139 & $2050 \mathrm{BC}$ & $20.2 \pm 1.4$ & $3725 \pm 11$ & BP 3999 \\
\hline $1210 \mathrm{BC}$ & $10.5 \pm 1.4$ & $2986 \pm 11$ & BP 3159 & $2070 \mathrm{BC}$ & $21.7 \pm 1.6$ & $3733 \pm 13$ & BP 4019 \\
\hline $1230 \mathrm{BC}$ & $9.4 \pm 1.6$ & $3014 \pm 13$ & BP 3179 & $2090 \mathrm{BC}$ & $30.1 \pm 1.7$ & $3687 \pm 13$ & BP 4039 \\
\hline $1250 \mathrm{BC}$ & & $2977 \pm 12$ & BP 3199 & 2110 BC & $32.4 \pm 1.6$ & $3688 \pm 13$ & BP 4059 \\
\hline $1270 \mathrm{BC}$ & $9.9 \pm 1.8$ & $3049 \pm 14$ & BP 3219 & $2130 \mathrm{BC}$ & $31.8 \pm 1.9$ & $3713 \pm 15$ & BP 4079 \\
\hline 1290 BC & $14.0 \pm 1.8$ & $3036 \pm 14$ & BP 3239 & $2150 \mathrm{BC}$ & $24.7 \pm 1.3$ & $3788 \pm 10$ & BP 4099 \\
\hline $1310 \mathrm{BC}$ & $14.1 \pm 1.8$ & $3054 \pm 15$ & BP 3259 & $2170 \mathrm{BC}$ & $31.6 \pm 1.6$ & $3753 \pm 13$ & BP 4119 \\
\hline $1330 \mathrm{BC}$ & $10.4 \pm 1.7$ & $3103 \pm 13$ & BP 3279 & $2190 \mathrm{BC}$ & $31.9 \pm 1.2$ & $3770 \pm 9$ & BP 4139 \\
\hline
\end{tabular}


TABLE 1. (Continued)

\begin{tabular}{|c|c|c|c|c|c|c|c|}
\hline Cal $\mathrm{AD} / \mathrm{BC}$ & $\Delta{ }^{14} \mathrm{C} \% 0$ & $\begin{array}{c}{ }^{14} \mathrm{C} \\
\text { age (BP) }\end{array}$ & Cal BP & Cal $\mathrm{AD} / \mathrm{BC}$ & $\Delta^{14} \mathrm{C} \% 0$ & $\begin{array}{l}{ }^{14} \mathrm{C} \\
\text { age (BP) }\end{array}$ & Cal BP \\
\hline 2210 BC & $26.8 \pm 1.4$ & $3829 \pm 11$ & BP 4159 & $2370 \mathrm{BC}$ & $37.2 \pm 1.5$ & $3903 \pm 11$ & BP 4319 \\
\hline $2230 \mathrm{BC}$ & $30.9 \pm 1.5$ & $3817 \pm 12$ & BP 4179 & 2390 вС & $43.6 \pm 1.7$ & $3874 \pm 13$ & BP 4339 \\
\hline $2250 \mathrm{BC}$ & $33.7 \pm 1.4$ & $3814 \pm 11$ & BP 4199 & 2410 BC & $39.9 \pm 1.4$ & $3922 \pm 11$ & BP 4359 \\
\hline 2270 BC & $37.5 \pm 1.9$ & $3804 \pm 15$ & BP 4219 & 2430 BC & $44.7 \pm 0.9$ & $3904 \pm 7$ & BP 4379 \\
\hline 2290 вC & $33.6 \pm 1.6$ & $3853 \pm 12$ & BP 4239 & 2450 BC & $48.0 \pm 1.7$ & $3899 \pm 12$ & BP 4399 \\
\hline $2310 \mathrm{BC}$ & $35.8 \pm 1.8$ & $3856 \pm 14$ & BP 4259 & 2470 вС & $38.8 \pm 1.5$ & $3988 \pm 12$ & BP 4419 \\
\hline 2330 BC & $36.3 \pm 1.5$ & $3872 \pm 11$ & BP 4279 & 2490 BC & $39.5 \pm 1.5$ & $4002 \pm 12$ & BP 4439 \\
\hline $2350 \mathrm{BC}$ & $36.2 \pm 1.6$ & $3892 \pm 13$ & BP 4299 & & & & \\
\hline
\end{tabular}

